\title{
Retrieval of the Complete Coding Sequence of the UK-Endemic Tatenale Orthohantavirus Reveals Extensive Strain Variation and Supports Its Classification as a Novel Species
}

\author{
Joseph G. Chappell ${ }^{1}$, Theocharis Tsoleridis ${ }^{1}$, Okechukwu Onianwa ${ }^{1}$, Gabby Drake ${ }^{2}$, \\ Ian Ashpole ${ }^{2}$, Phillipa Dobbs ${ }^{3}$, William Edema ${ }^{1}$, Frederick Kumi-Ansah ${ }^{1}$, Malcolm Bennett ${ }^{4}$, \\ Rachael E. Tarlinton ${ }^{4}$, Jonathan K. Ball ${ }^{1, *}$ and C. Patrick McClure ${ }^{1}$ (D) \\ 1 School of Life Sciences, University of Nottingham, Nottingham NG7 2UH, UK; \\ joseph.chappell1@nottingham.ac.uk (J.G.C.); Patrick.Mcclure@nottingham.ac.uk (C.P.M.) \\ 2 Chester Zoo, Chester, Cheshire CH2 1EU, UK \\ 3 Twycross Zoo, Atherstone, Warwickshire CV9 3PX, UK \\ 4 School of Veterinary Science, University of Nottingham, Sutton Bonnington, Loughborough LE12 5RD, UK \\ * Correspondence: mrzjb@exmail.nottingham.ac.uk; Tel.: +44-(0)-115-823-0745; Fax: +44-(0)-115-823-0759
}

Received: 26 February 2020; Accepted: 13 April 2020; Published: 17 April 2020

\begin{abstract}
Orthohantaviruses are globally distributed viruses, associated with rodents and other small mammals. However, data on the circulation of orthohantaviruses within the UK, particularly the UK-endemic Tatenale virus, is sparse. In this study, 531 animals from five rodent species were collected from two locations in northern and central England and screened using a degenerate, pan- orthohantavirus RT-PCR assay. Tatenale virus was detected in a single field vole (Microtus agrestis) from central England and twelve field voles from northern England. Unbiased high-throughput sequencing of the central English strain resulted in the recovery of the complete coding sequence of a novel strain of Tatenale virus, whilst PCR-primer walking of the northern English strain recovered almost complete coding sequence of a previously identified strain. These findings represented the detection of a third lineage of Tatenale virus in the United Kingdom and extended the known geographic distribution of these viruses from northern to central England. Furthermore, the recovery of the complete coding sequence revealed that Tatenale virus was sufficiently related to the recently identified Traemersee virus, to meet the accepted criteria for classification as a single species of orthohantavirus.
\end{abstract}

Keywords: Orthohantavirus; hantavirus; high-throughput sequencing; virus discovery; field vole; United Kingdom

\section{Introduction}

Orthohantaviruses are a large and diverse genus of viruses, belonging to the Hantaviridae family within the order Bunyavirales. The genome of orthohantaviruses consists of a linear, negative-sensed and single-stranded RNA, divided into three segments. The large (L) segment encodes a single RNA-dependent RNA polymerase, the medium (M) segment encodes a glycoprotein precursor and the small (S) segment encodes a nucleocapsid protein [1]. Historically, orthohantaviruses have predominantly been associated with rodent reservoir species [2]; however, they have increasingly been detected in other mammalian taxa, such as bats [3], shrews [4] and moles [5]. Each species of orthohantavirus is typically associated with a single reservoir species, where the infection is considered to be persistent and asymptomatic [6]. 
Several orthohantavirus species are capable of transmission into humans, through the inhalation of aerosolised contaminated excreta [7]. Human infection is thought to result in two forms of the disease, depending on the causative species; old-world species are associated with a primarily renal syndrome known as 'haemorrhagic fever with renal syndrome' (HFRS), whilst new-world species are associated with pulmonary disease, 'hantavirus pulmonary syndrome' (HPS) [8]. However, an overlap of clinical presentations between the two syndromes has led to suggestions that they should be reconsidered as a single clinical syndrome, hantavirus fever (HF) [9]. The severity of HF can vary significantly; Puumala virus (PUUV) infection, for example, causes a mild, often sub-clinical disease [10], whilst new-world species, such as Sin Nombre virus (SNV), has a case fatality rate of $35 \%$ [11]. There are four species known to cause HF in Europe; Seoul (SEOV), Dobrava-Belgrade (DOBV), Tula (TULV) and Puumala (PUUV) [12]; the reservoirs associated with these viruses are the brown rat (Rattus norvegicus), yellow-necked mouse (Apodemus flavicollis)/striped field mouse (Apodemus agrarius), common vole (Microtus arvalis) and the bank vole (Myodes glareolus), respectively. Except for the TULV-associated common vole, which is geographically restricted to the Orkney Islands in Scotland, each of the reservoir species associated with these viruses are present in the United Kingdom (UK). However, of these viruses, only SEOV has been detected in the UK [13].

HF has been reported sporadically throughout the UK, including England [14], Scotland [15] and Northern Ireland [16], though the causative species could not be confirmed due to cross-reactivity of the serological assays used to diagnose the orthohantavirus infections [17]. The first orthohantavirus linked to HF in the UK was in 2011 when a novel strain of SEOV was isolated from wild rats captured on the farm of a patient with suspected HF [18]; SEOV was then detected in pet rats belonging to a patient with serologically confirmed HF in 2013 [19]. Furthermore, a novel vole-associated hantavirus related to TULV and PUUV—Tatenale virus (TATV) — was identified in field voles (Microtus agrestis) captured in northwest England in 2013 [20] and again in northern England in 2017 [21]. However, fragments of less than 400 nucleotides were retrieved for two of the three genomic segments, meaning that phylogenetic analysis of this virus was limited. In 2019, an orthohantavirus was detected in German field voles-Traemersee virus (TRAV) — and was suggested to be a strain of Tatenale virus. However, the aforementioned paucity of published TATV sequence data has precluded any accurate comparison between TATV and TRAV [22]. To better understand the prevalence and phylogeny of Tatenale virus, we performed in-depth sampling and analysis of various rodents living in the UK.

\section{Materials and Methods}

\subsection{Samples}

Rodents were caught at two semirural sites in the UK: Leicestershire (Site 1, 52.6524 ${ }^{\circ} \mathrm{N}$, $1.5291^{\circ} \mathrm{W}$ ) and Cheshire (Site 2, 53.2273 $\mathrm{N}, 2.8844^{\circ} \mathrm{W}$ ). Seventy-two rats (Rattus norvegicus), 224 mice (Mus musculus) and 12 field voles (Microtus agrestis) were collected from Site 1 between May 2013 and October 2014. Eight rats, 119 field voles, 93 wood mice (Apodemus flavicollis) and 3 bank voles (Myodes glareolus) were collected from Site 2 between June 2013 and July 2016.

Rodents were captured as part of routine pest-management at both sites. Ethical approval for collection of rodent tissue had been previously been granted [23] by the University of Nottingham School of Veterinary Science Ethical Panel, reference numbers 1602151102 and 1786160518.

\subsection{Nucleic Acid Preparation}

Sections of lung and kidney tissue, approximately $1 \mathrm{~mm}^{3}$ were collected, and RNA was extracted using GenElute ${ }^{\mathrm{TM}}$ mammalian total RNA miniprep kit (Sigma Aldrich, St Louis, MO, USA), following the provided protocol. RNA was quantified using a NanoDrop spectrophotometer (ThermoFisher Scientific, Waltham, MA, USA). cDNA was synthesised from the RNA using RevertAid reverse transcriptase (ThermoFisher Scientific) following the provided protocol. 


\subsection{RT-PCR Screening}

Two-step RT-PCR was performed on the samples, using a degenerate primer pair (HanSemiF: GAATATATATCNTAYGGDGGDGA and HanSemiR: CTGGTGACCAYTTNGTNGCAT) designed in-house to target a $178 \mathrm{bp}$ region of the $\mathrm{L}$ segment of all known hantaviruses. PCR reactions contained $0.5 \mu \mathrm{L}$ of cDNA, added to $1.25 \mu \mathrm{L} 10 \times$ PCR buffer, $0.06 \mu \mathrm{L}$ of HotStarTaq DNA polymerase (QIAGEN, Hilden, Germany), $0.5 \mu \mathrm{L} 10 \mathrm{mM}$ dNTP's (Sigma Aldrich), $0.5 \mu \mathrm{L}$ each of forward and reverse primer $(10 \mathrm{Pmol} / \mu \mathrm{L})$, and $9.19 \mu \mathrm{L}$ of water for a total volume of $12.5 \mu \mathrm{L}$. Cycling conditions were $95^{\circ} \mathrm{C}$ for $15 \mathrm{~min}, 55$ cycles of $94{ }^{\circ} \mathrm{C}, 51^{\circ} \mathrm{C}$ and $72{ }^{\circ} \mathrm{C}$ for $20 \mathrm{~s}$ each, followed by $72{ }^{\circ} \mathrm{C}$ for $10 \mathrm{~min}$.

A second degenerate pan-hantavirus assay, targeting a different, larger region of the L segment, was used to confirm positive PCR results. Primers were sourced from Klempa et al. [24] (Han-L-F1: ATGTAYGTBAGTGCWGATGC and Han-L-R1: AACCADTCWGTYCCRTCATC); PCR reactions contained the same concentration of reagents and primers; cycling conditions were modified to $95^{\circ} \mathrm{C}$ for $15 \mathrm{~min}$, followed by 55 cycles of $94{ }^{\circ} \mathrm{C}(30 \mathrm{~s}), 53{ }^{\circ} \mathrm{C}(50 \mathrm{~s})$ and $72{ }^{\circ} \mathrm{C}(30 \mathrm{~s})$, finished with a final extension of $72{ }^{\circ} \mathrm{C}(10 \mathrm{~min})$. This assay produced an amplicon of $452 \mathrm{bp}$.

\subsection{High-Throughput Sequencing}

The orthohantavirus positive field vole from Site 1 was selected for high-throughput sequencing (HTS). NEBNext ${ }^{\circledR}$ rRNA depletion kit (Human/Mouse/Rat) (New England Biolabs, Ipswich, MA, USA) with RNA sample purification beads (New England Biolabs, Ipswich, MA, USA) was used to deplete host ribosomal RNA from the sample. Sequencing libraries were then created from the depleted RNA using NEBNext ${ }^{\circledR}$ Ultra $^{\mathrm{TM}}$ II directional RNA library prep kit for Illumina (New England Biolabs). Libraries were sent to SourceBioscience (Nottingham, UK) and sequenced with an Illumina HiSeq 4000. Each read length was $2 \times 150 \mathrm{bp}$, and the insert size was $200 \mathrm{bp}$ on average. All generated sequence data were analysed using the Geneious Prime 2019.0.4. Generated reads were mapped to reference orthohantavirus sequences downloaded from GenBank.

\subsection{Retrieval of TATV's Complete Coding sequence (CDS) Using PCR Primer-Walking}

The complete coding sequences (CDS) of the Tatenale virus retrieved via HTS was used as a reference sequence to design primers to retrieve the CDS of the TATV strain from Site 2, as funding was not available for HTS of both samples.

\subsection{Phylogenetic Analysis}

Nucleotide sequences for each segment of both TATV strains were aligned with a full-length coding sequence for representative Arvicolinae-associated orthohantaviruses and a non-arvicolinae orthohantavirus (Andes Virus) outgroup, using the MUSCLE function in MEGAX [25]. MEGAX was then used to find the best-fit substitution model for each alignment of sequences, and the model with the lowest Bayesian information criterion scores was considered the most appropriate.

Maximum likelihood trees were created with a GTR+G+I model, using MEGAX software. Robustness was assessed using bootstrap resampling (1000 replicates).

The pairwise evolutionary distance (PED) values of TATV and related orthohantaviruses were calculated using a WAG amino acid substitution model, in the PhyML [26] plugin on Geneious Prime. These calculations were based on a concatenation of the complete coding regions of $\mathrm{S}$ and $\mathrm{M}$ segments from the same virus. 


\section{Results}

\subsection{Detection of Orthohantavirus RNA by RT-PCR}

Orthohantavirus RNA was detected in a single field vole from Site $1(8.3 \%)$ and twelve field voles from Site $2(10 \%)$. No orthohantavirus was detected in any house mouse $(n=224)$, wood mouse $(\mathrm{N}=93)$, brown rat $(n=80)$ or bank vole $(n=3)$ samples.

The sequenced HAN-L amplicons from the Site 2 voles were highly conserved; the two most dissimilar were $97.7 \%$ identical at the nucleotide level. Comparison of the HAN-L amplicons between the two sites were more divergent, with a nucleotide homology of $86.3 \%$ to $89.3 \%$ between the single Site 1 virus and Site 2 viruses. We named the strain from Site 1 'Norton-Juxta' and the strain from Site 2 'Upton-Heath', reflecting the geographic origins of the two strains.

BLASTn searches of the 452 bp HAN-L PCR amplicons showed a high level of similarity to Tatenale orthohantaviruses. The Norton-Juxta strain was $87.3 \%$ identical to 'Tatenale virus strain B41' and $86.5 \%$ identical to 'Kielder hantavirus kld-1' at the nucleotide level, whilst the Upton-Heath Strains were $94.9-96.9 \%$ identical to B41 and $84-86.6 \%$ identical to kld-1.

\subsection{Recovery of Complete TATV CDS}

A total of $62,191,960$ reads were sequenced from an uHTS library created from the lung tissue of the Norton-Juxta positive field vole. A total of 27,279,217 reads remained following pair-merging and quality processing. Mapping of these reads to reference sequences for each segment resulted in a total of 94,706 reads, representing $2.5 \%$ of filtered reads. The complete coding sequence of each segment was recovered. The L segment was 6465 nucleotides in length (Genbank Accession number MK883761), whilst the M segment was 3447 nucleotides (MK883759), and the CDS of S was 1302 nucleotides (MK883757).

Complete CDS of the L (MK883760) and S (MK883756) segments of TATV Upton-Heath was recovered through PCR primer-walking, these sequences were the same length as those for TATV Norton-Juxta. Almost complete CDS of the M segment (MK883758) was recovered, missing 90 nucleotides from the $3^{\prime}$ end of the CDS.

\subsection{Analysis of Complete TATV CDS}

Comparison of the complete $\mathrm{L}$ and $\mathrm{S}$ segments and almost-complete $\mathrm{M}$ segments of the two strains revealed a nucleotide similarity of 90.6\%, 94.1\%, and 91.3\%, respectively. Phylogenetic analysis of the three segments, with complete Arvicolinae-associated orthohantaviruses, showed that both Norton-Juxta and Upton-Heath TATV clustered closely with Traemersee virus, forming a distinct clade, and supported with strong bootstrap values in the L (Figure 1A), M (Figure 1B) and S segments (Figure 1C). Nucleotide and amino acid similarities between both TATV strains and closely related orthohantavirus species are shown in Table 1. Pairwise evolutionary distance (PED) analysis of the concatenated S and M segments of Norton-Juxta and other vole-borne orthohantaviruses showed values of between 0.12 and 0.27 . The PED values between Norton-Juxta and TRAV were 0.05.

Comparison with the partial S sequence of TATV-B41 showed a nucleotide similarity of $98.7 \%$ with Upton-Heath and 93.9\% with Norton-Juxta. Phylogenetic analysis with the partial L and S segments for other TATV strains showed that Norton-Juxta formed a novel lineage in the phylogenies of both segments, whilst Upton-Heath clustered closely with the previous B41 strain (Supplementary Figure S1). 


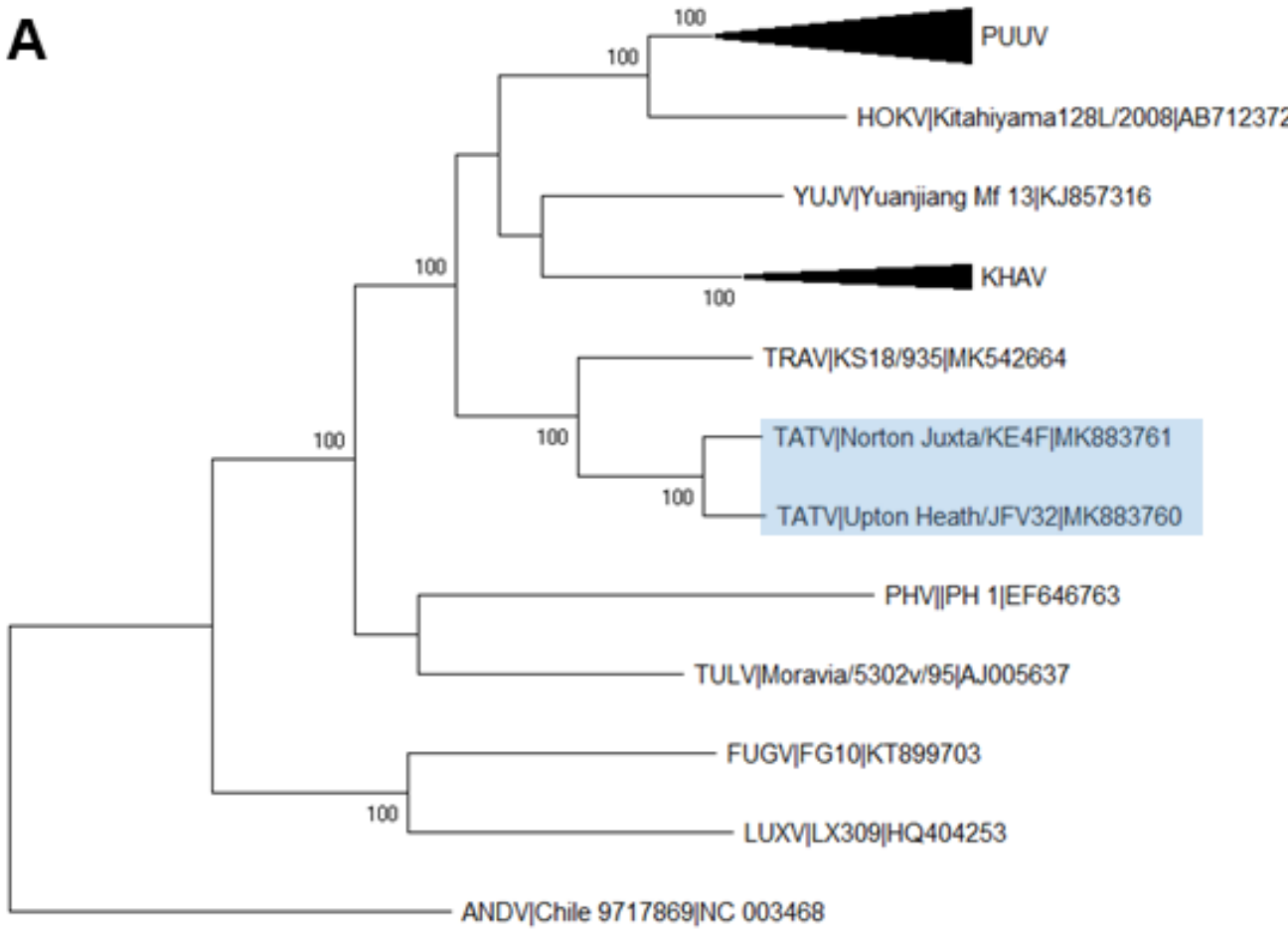

0.20

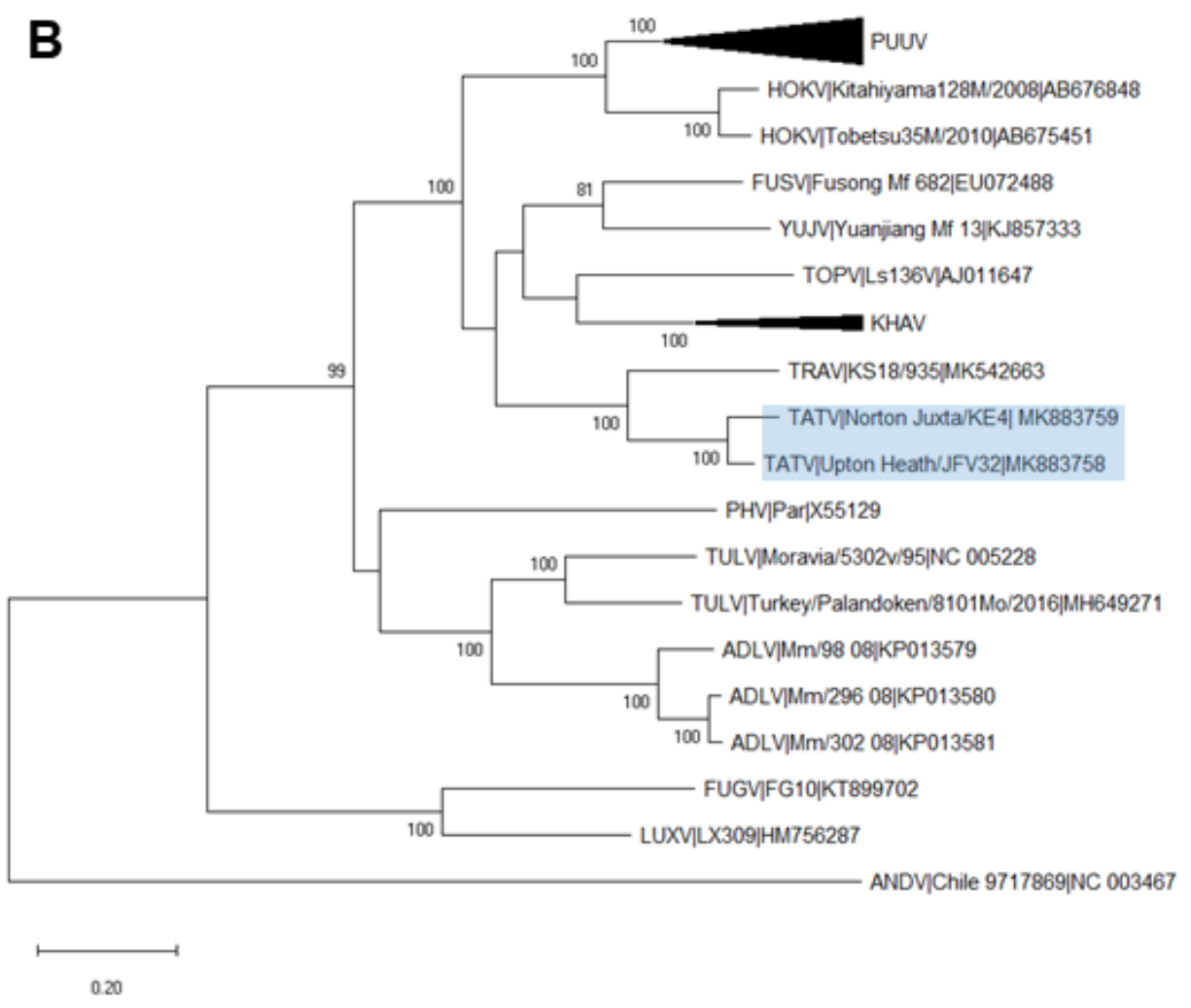

Figure 1. Cont. 


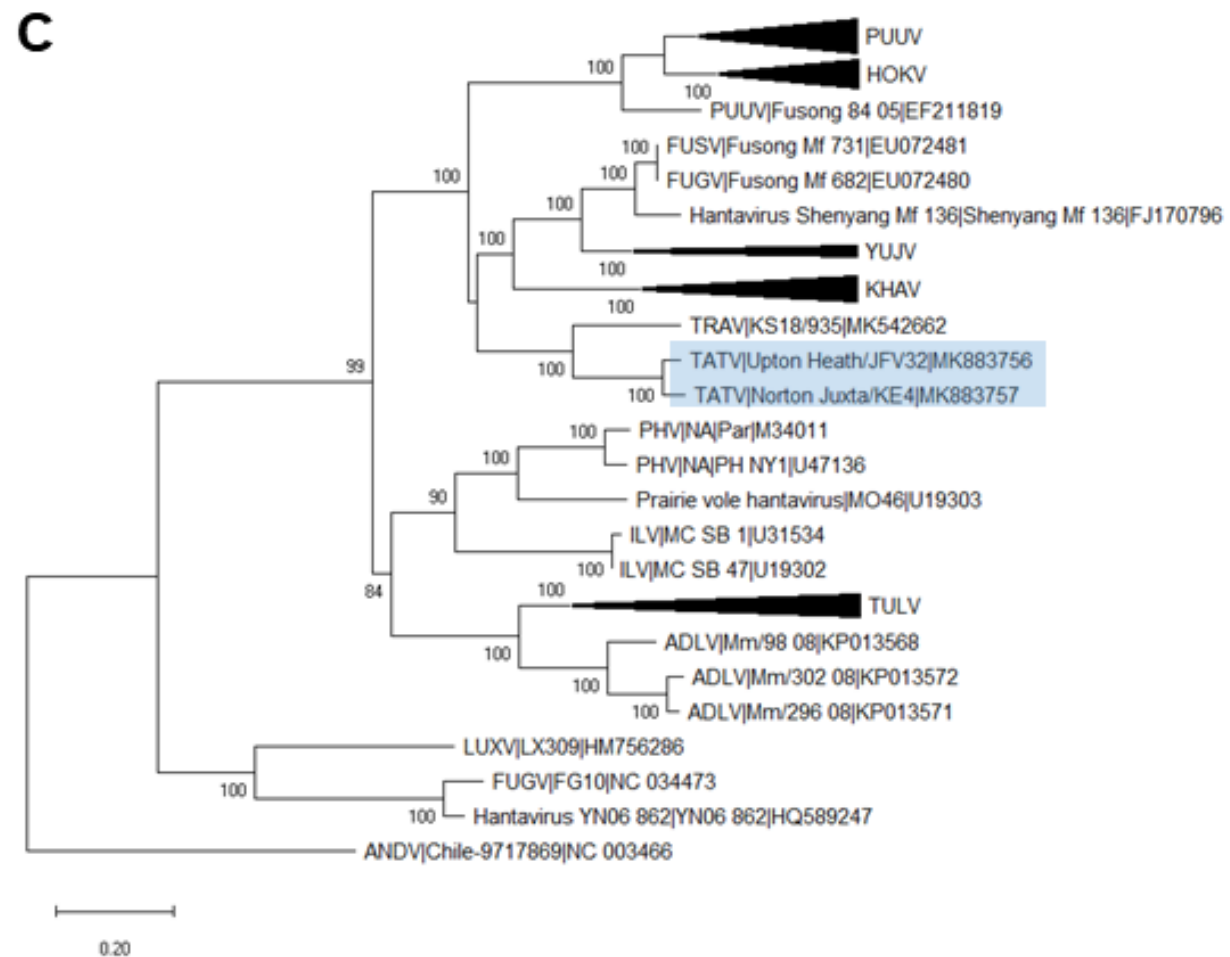

Figure 1. Phylogenetic relationship of Tatenale virus with other vole-associated orthohantavirus species. Representative complete coding sequences were retrieved for each segment; L (A), M (B) and S (C). Maximum likelihood trees were created with a GTR+G+I model, using MEGAX software. Branch lengths were drawn to a scale of nucleotide substitutions per site. $\mathrm{L}$ and $\mathrm{S}$ trees were based on full-length sequences, whilst the $\mathrm{M}$ segment tree was based on the available sequence for the partial Upton-Heath strain. Numbers above individual branches show bootstrap support after 1000 replicates. Tatenale virus strains are highlighted with a blue box. Black triangles represent a compressed species-specific subtree. Sequences are shown with the species name, strain name and the GenBank accession number. PUUV, Puumala virus; HOKV, Hokkaido virus; FUSV, Fusong virus; YUJV, Yuanjiang virus; KHAV, Khabarovsk virus; TOPV, Topografov virus; TATV, Tatenale virus; TRAV, Traemmersee virus; PHV, Prospect Hill virus; ILV, Isla Vista virus; TULV, Tula virus; ADLV, Adler virus; LUXV, Luxi virus; FUGV, Fugong virus; ANDV, Andes virus.

Table 1. The similarity of Norton-Juxta and Upton-Heath strains of Tatenale virus to the closest related strain of the most related species at nucleotide (amino acid) level. Similarities to the M segment of the Upton-Heath strain are based on the available partial sequence. * Indicates no complete sequence data available.

\begin{tabular}{cccc}
\hline Species (Accession Number) & $\boldsymbol{S}$ & $\boldsymbol{M}$ & $\boldsymbol{L}$ \\
\hline & \multicolumn{3}{c}{ Norton-Juxta } \\
Traemersee & $82.7(96.8)$ & $79.8(94.2)$ & $81.5(96.4)$ \\
Khabarovsk & $79.2(89.4)$ & $76.4(87.5)$ & $77.9(90.9)$ \\
Yuanjiang & $79.2(88.5)$ & $75.3(86.5)$ & $77.7(90.4)$ \\
Fusong & $78.7(88.2)$ & $75.2(85.9)$ & $-^{*}$ \\
Puumala & $77.9(87.8)$ & $74.8(84.7)$ & $77.9(88.1)$ \\
Hokkaido & $78.3(87.5)$ & $75.5(84.4)$ & $76.8(88.5)$ \\
& \multicolumn{3}{c}{ Upton-Heath } \\
Traemersee & $83(96.5)$ & $80.8(94.3)$ & $81.5(96.4)$ \\
Khabarovsk & $79.9(88.9)$ & $77.1(87.8)$ & $78(90.7)$ \\
Yuanjiang & $78.9(88.2)$ & $75.7(86.5)$ & $77.7(89.6)$ \\
Fusong & $78.9(88)$ & $76(86.2)$ & $-{ }^{*}$ \\
Puumala & $78.4(87.8)$ & $75.5(84.6)$ & $77.6(87.5)$ \\
Hokkaido & $79(87.8)$ & $75.7(84.4)$ & $76.7(87.9)$ \\
\hline
\end{tabular}




\section{Discussion}

This was the first reported recovery of complete coding sequences for TATV in the UK. Based on a genetic divergence, we proposed that this virus represented an additional strain of TATV, tentatively called Norton-Juxta, which extended the known range of TATV from northern to central England. The detection of diverse TATV in field voles, but not other species of rodents sampled from the same sites, strengthened evidence of field voles as the primary reservoir of the virus. The high similarity between the available sequence data for TATV B41 and the corresponding sequence from TATV Upton-Heath, together with the close geographic proximity of the collection sites, indicated that the two viruses might be co-circulating within the same population of field voles.

Orthohantavirus species' demarcation criteria of $>7 \%$ AA divergence across $\mathrm{S}$ and $\mathrm{M}$ segments [27], as well as stricter criteria of a PED lower than 0.1 in the concatenated S and M segments [28], have been suggested. As the PED values between the complete Norton-Juxta strain of TATV and TRAV was below the 0.1 speciation threshold, this confirmed that both TATV and TRAV were members of the same viral species, as was hypothesised by Jeske et al. [22]. Though TRAV was the first strain with complete CDS, TATV was detected several years prior and is more established in the literature. Thus, we proposed that the species in which TATV and TRAV belonged to be named Tatenale orthohantavirus.

There is serological evidence of human infection with PUUV- or SNV-like viruses in the UK [29], though there has been no molecular evidence of these viruses in either humans or rodents. A previous study has reported that blood from a vole infected with TATV B41 is cross-reactive with PUUV, which suggests that PUUV/SNV seropositive humans may have been the result of TATV infection [20]. Until now, the paucity of sequence data has precluded significant further investigation of TATV. Recovery of the complete coding sequence for each of the segments, particularly the glycoproteins encoded in the M segment, will allow for in vitro studies to further explore the zoonotic potential of the virus.

Supplementary Materials: Supplementary materials can be found at http://www.mdpi.com/1999-4915/12/4/454/s1.

Author Contributions: J.G.C., C.P.M., J.K.B. and R.E.T. conceived and designed experiments. J.G.C., O.O., W.E., T.T. and F.K.-A. performed experiments. G.D., I.A., P.D. and M.B. provided samples. J.G.C. and T.T. analysed HTS data. J.G.C. wrote the manuscript. All authors have read and agreed to the published version of the manuscript.

Funding: This research was funded by the Medical Research Council studentship award, grant number 1651320.

Conflicts of Interest: The authors declare no conflict of interest. The funders had no role in the design of the study; in the collection, analyses, or interpretation of data; in the writing of the manuscript, or in the decision to publish the results.

\section{References}

1. Plyusnin, A.; Vapalahti, O.; Vaheri, A. Hantaviruses: Genome structure, expression and evolution. J. Gen. Virol. 1996, 77, 2677-2687. [CrossRef] [PubMed]

2. Jonsson, C.B.; Figueiredo, L.T.M.; Vapalahti, O. A global perspective on hantavirus ecology, epidemiology, and disease. Clin. Microbiol. Rev. 2010, 23, 412-441. [CrossRef] [PubMed]

3. Weiss, S.; Witkowski, P.T.; Auste, B.; Nowak, K.; Weber, N.; Fahr, J. Hantavirus in Bat, Sierra Leone. Emerg. Infect. Dis. 2012, 18, 159-161. [CrossRef] [PubMed]

4. Klempa, B.; Fichet-Calvet, E.; Lecompte, E.; Auste, B.; Aniskin, V.; Meisel, H.; Barrière, P.; Koivogui, L.; ter Meulen, J.; Krüger, D.H. Novel hantavirus sequences in Shrew, Guinea. Emerg. Infect. Dis. 2007, 13, 520-522. [CrossRef]

5. Laenen, L.; Vergote, V.; Kafetzopoulou, L.E.; Wawina, T.B.; Vassou, D.; Cook, J.A.; Hugot, J.-P.; Deboutte, W.; Kang, H.J.; Witkowski, P.T.; et al. A Novel Hantavirus of the European Mole, Bruges Virus, Is Involved in Frequent Nova Virus Coinfections. Genome Biol. Evol. 2018, 10, 45-55. [CrossRef]

6. Ermonval, M.; Baychelier, F.; Tordo, N. What Do We Know about How Hantaviruses Interact with Their Different Hosts? Viruses 2016, 8, 223. [CrossRef]

7. Vaheri, A.; Strandin, T.; Hepojoki, J.; Sironen, T.; Henttonen, H.; Mäkelä, S.; Mustonen, J. Uncovering the mysteries of hantavirus infections. Nat. Rev. Microbiol. 2013, 11, 539-550. [CrossRef] 
8. Macneil, A.; Nichol, S.T.; Spiropoulou, C.F. Hantavirus pulmonary syndrome. Virus Res. 2011, 162, $138-147$. [CrossRef]

9. Clement, J.; Maes, P.; Van Ranst, M. Hemorrhagic Fever with Renal Syndrome in the New, and Hantavirus Pulmonary Syndrome in the old world: Paradi(se)gm lost or regained? Virus Res. 2014, 187, 55-58. [CrossRef]

10. Hjertqvist, M.; Klein, S.L.; Ahlm, C.; Klingstrom, J. Mortality rate patterns for hemorrhagic fever with renal syndrome caused by Puumala virus. Emerg. Infect. Dis. 2010, 16, 1584-1586. [CrossRef]

11. MacNeil, A.; Ksiazek, T.G.; Rollin, P.E. Hantavirus pulmonary syndrome, United States, $1993-2009$. Emerg. Infect. Dis. 2011, 17, 1195-1201. [CrossRef] [PubMed]

12. Heyman, P.; Ceianu, C.; Christova, I.; Tordo, N.; Beersma, M.; Joao Alves, M.; Lundkvist, A.; Hukic, M.; Papa, A.; Tenorio, A.; et al. A five-year perspective on the situation of haemorrhagic fever with renal syndrome and status of the hantavirus reservoirs in Europe, 2005-2010. Eurosurveillance 2011, 16. [CrossRef]

13. Murphy, E.G.; Williams, N.J.; Bennett, M.; Jennings, D.; Chantrey, J.; McElhinney, L.M. Detection of Seoul virus in wild brown rats (Rattus norvegicus) from pig farms in Northern England. Vet. Rec. 2019, 184, 525. [CrossRef] [PubMed]

14. Watson, A.R.; Irving, W.L.; Ansell, I.D. Playing in a scrapyard and acute renal failure. Lancet 1997, $349,1446$. [CrossRef]

15. Walker, E.; Boyd, A.J.; Kudesia, G.; Pinkerton, I.W. A Scottish case of nephropathy due to Hantaan virus infection. J. Infect. 1985, 11, 57-58. [CrossRef]

16. McKenna, P.; Clement, J.; Matthys, P.; Coyle, P.V.; McCaughey, C. Serological evidence of hantavirus disease in Northern Ireland. J. Med. Virol. 1994, 43, 33-38. [CrossRef] [PubMed]

17. Brus Sjölander, K.; Lundkvist, Å. Dobrava virus infection: Serological diagnosis and cross-reactions to other hantaviruses. J. Virol. Methods 1999, 80, 137-143. [CrossRef]

18. Jameson, L.J.; Logue, C.H.; Atkinson, B.; Baker, N.; Galbraith, S.E.; Carroll, M.W.; Brooks, T.; Hewson, R. The continued emergence of hantaviruses: Isolation of a Seoul virus implicated in human disease, United Kingdom, October 2012. Eurosurveillance 2013, 18, 20344.

19. Jameson, L.J.; Taori, S.K.; Atkinson, B.; Levick, P.; Featherstone, C.A.; van der Burgt, G.; McCarthy, N.; Hart, J.; Osborne, J.C.; Walsh, A.L.; et al. Pet rats as a source of hantavirus in England and Wales, 2013. Eurosurveillance 2013, 18, 20415.

20. Pounder, K.C.; Begon, M.; Sironen, T.; Henttonen, H.; Watts, P.C.; Voutilainen, L.; Vapalahti, O.; Klempa, B.; Fooks, A.R.; McElhinney, L.M. Novel Hantavirus in Field Vole, United Kingdom. Available online: http://wwwnc.cdc.gov/eid/article/19/4/12-1057_article (accessed on 22 January 2016).

21. Thomason, A.G.; Begon, M.; Bradley, J.E.; Paterson, S.; Jackson, J.A. Endemic Hantavirus in Field Voles, Northern England. Emerg. Infect. Dis. 2017, 23, 1033-1035. [CrossRef]

22. Jeske, K.; Hiltbrunner, M.; Drewes, S.; Ryll, R.; Wenk, M.; Špakova, A.; Petraitytè-Burneikienė, R.; Heckel, G.; Ulrich, R.G. Field vole-associated Traemmersee hantavirus from Germany represents a novel hantavirus species. Virus Genes 2019, 55, 1-6. [CrossRef] [PubMed]

23. Tsoleridis, T.; Chappell, J.G.; Monchatre-Leroy, E.; Umhang, G.; Shi, M.; Bennett, M.; Tarlinton, R.E.; McClure, C.P.; Holmes, E.C.; Ball, J.K. Discovery and prevalence of divergent RNA viruses in European field voles and rabbits. Viruses 2019, 12, 47. [CrossRef] [PubMed]

24. Klempa, B.; Fichet-Calvet, E.; Lecompte, E.; Auste, B.; Aniskin, V.; Meisel, H.; Denys, C.; Koivogui, L.; ter Meulen, J.; Krüger, D.H. Hantavirus in African wood mouse, Guinea. Emerg. Infect. Dis. 2006, 12, 838-840. [CrossRef] [PubMed]

25. Kumar, S.; Stecher, G.; Li, M.; Knyaz, C.; Tamura, K. MEGA X: Molecular Evolutionary Genetics Analysis across Computing Platforms. Mol. Biol. Evol. 2018, 35, 1547-1549. [CrossRef] [PubMed]

26. Guindon, S.; Dufayard, J.F.; Lefort, V.; Anisimova, M.; Hordijk, W.; Gascuel, O. New algorithms and methods to estimate maximum-likelihood phylogenies: Assessing the performance of PhyML 3.0. Syst. Biol. 2010, 59, 307-321. [CrossRef]

27. ICTV ICTV Ninth Report; Taxonomy Release. 2009. Available online: https://talk.ictvonline.org/ictvreports/ictv_9th_report/negative-sense-rna-viruses-2011/w/negrna_viruses/205/bunyaviridae (accessed on 7 March 2019). 
28. Maes, P.; Klempa, B.; Clement, J.; Matthijnssens, J.; Gajdusek, D.C.; Krüger, D.H.; Van Ranst, M. A proposal for new criteria for the classification of hantaviruses, based on $\mathrm{S}$ and $\mathrm{M}$ segment protein sequences. Infect. Genet. Evol. 2009, 9, 813-820. [CrossRef]

29. Jameson, L.J.; Newton, A.; Coole, L.; Newman, E.N.C.; Carroll, M.W.; Beeching, N.J.; Hewson, R.; Christley, R.M. Prevalence of antibodies against hantaviruses in serum and saliva of adults living or working on farms in Yorkshire, United Kingdom. Viruses 2014, 6, 524-534. [CrossRef]

(C) 2020 by the authors. Licensee MDPI, Basel, Switzerland. This article is an open access article distributed under the terms and conditions of the Creative Commons Attribution (CC BY) license (http://creativecommons.org/licenses/by/4.0/). 